Media Industries $5.2(2018)$

\title{
Creating Children's Television for SVODs: The Alignment of Global Production Practices with National Screen Policies in the Netflix Original Bottersnikes and Gumbles ${ }^{1}$
}

\author{
Anna Potter ${ }^{2}$ \\ UNIVERSITY OF THE SUNSHINE COAST \\ Apotter [AT] usc.edu.au
}

\begin{abstract}
In many countries, domestically produced children's television is believed to play an important role in national cultural representation. But national policy settlements and funding schemes designed to support its production are aging rapidly and do not apply to internet-distributed television services. Using the case study of one of Netflix's first children's Originals, the Australian animation Bottersnikes and Gumbles, this article analyzes the impact of subscription video on demand (SVOD) services on children's screen production industries and their practitioners' creative practice. It reveals how the global SVOD's operations intersect with national policy instruments and explains the production collaborations developing between Netflix and public service broadcasters in the United Kingdom and Australia. The article's findings reveal that despite the advantages Netflix's large content budget and global distribution networks offer to children's content producers, domestic content quotas and the involvement of linear broadcasters remain vital to the funding and production of local children's television.
\end{abstract}

Keywords: Netflix, Children's Screen Production, Cultural Policy, Public Service Broadcasting

\section{Introduction}

In many countries, children's television is believed to play an important role in national cultural representation. ${ }^{3}$ Children, it is understood, benefit from watching television made 
especially for them, including locally produced television that helps socialize them into their own cultural context. Notwithstanding these traditions, the production, distribution, and consumption of children's television now occur within a globalized media environment in which screen content is increasingly distributed via the internet. Public service broadcasters (PSBs) face significant funding pressures, while streaming services such as Netflix, YouTube, and Amazon Prime are becoming more and more influential in the spaces of children's television. Subscription video on demand (SVOD) services, Netflix and Amazon Prime in particular, are investing heavily in children's content. These new online distributors represent an important source of additional license fees for producers, ${ }^{4}$ even as their means of distribution challenge the policy settlements intended to support locally produced children's content.

Focusing on the case study of one of Netflix's first ever children's Original commission, the Australian animated series Bottersnikes and Gumbles (2016), this article poses the following questions: First, how does the children's content commissioned and distributed by a global SVOD like Netflix intersect with national policy regimes intended to support children's television that contributes to national cultural representation? Second, how are the creative processes and production norms of children's television altered by Netflix's involvement in its funding and distribution? Finally, what kinds of coproduction arrangements and creative collaborations are developing between Netflix and PSBs in the United Kingdom and Australia?

Research into the relationship between children and television often concentrates on the audience, while television studies more broadly has tended to focus on texts, institutions, and audiences at the expense of industry practitioners. ${ }^{5}$ In contrast, the research presented here, which is grounded in a production studies model within a political economy tradition, pays close attention to the children's media industry players and practitioners: distributors, regulators, and production companies, with a particular focus on the creative practices of those working in the children's screen industries. In doing so, it draws on Steemers's ${ }^{6}$ construct of children's television as a subset of a broader television "production ecology" in which industrial, economic, creative, and regulatory elements interact with one another to shape the television that is produced for the contemporary child. This article also includes material from interviews undertaken with screen producers who are adapting to the needs of global streaming services while continuing to work within funding models and regulatory regimes largely grounded in predigital, national frameworks.

The article begins with a description of the case study, the computer-generated imagery (CGI) animated series Bottersnikes and Gumbles produced by Australian company Cheeky Little Media. It then examines the regulatory, industrial, and creative circumstances which affected the series' production to explain how the activities of global television services like Netflix intersect with local policy settings and longstanding production norms for children's television. The SVOD's creative collaboration with the BBC is also described, to illustrate some of the coproduction arrangements developing between Netflix and PSBs. The article concludes with a reminder of the imperative of state supports, including quotas, tax breaks, and direct funding measures, for the sustainability of domestically produced children's content. Despite Cheeky Little Media's deal with global SVOD Netflix, Bottersnikes and Gumbles would never have seen the light of day without a piece of Australian legislation first introduced in 1979, the Children's Television Standards (CTS). Its production is emblematic 
nonetheless of some of the "messy and complicated interactions"7 occurring in media industries between global SVOD services, national screen institutions, and creative practitioners.

\section{The Case Study of Bottersnikes and Gumbles}

Australian production company Cheeky Little Media was established in 2013 by David Webster and Patrick Egerton, who had previously worked together at Ambience Entertainment, a Sydney-based company with a broad production slate that includes children's content. During their time at Ambience Entertainment, they were responsible for the production of several animated series, including Erky Perky (2006) and The Adventures of Figaro Pho (2012). These series were commissioned by Australian free-to-air broadcasters to fill either local quota or public service obligations. They accessed Australian funding subsidies in the form of direct funding from leading screen agency Screen Australia for The Adventures of Figaro Pho and indirectly through the 20 percent television tax rebate scheme the Producer Offset for both productions. They also attracted investment from international children's channels-from the BBC and Nickelodeon in the case of The Adventures of Figaro Pho.

Bottersnikes and Gumbles, which is aimed at six- to nine-year-olds, is one of Cheeky Little Media's first productions. The CGI animation is loosely based on four Australian books written by Alexander Wakefield and illustrated by Desmond Digby, which were originally published in the 1970s. The stories are set in the Australian bush, the home of heroes the Gumbles, small furry animals not unlike koala bears, which can squash and stretch themselves into any shape. Arch enemies the Bottersnikes are lazy, destructive, and mean-spirited creatures that capture the Gumbles and put them to work whenever they can. Both creative director David Webster and executive producer Patrick Egerton had grown up reading the illustrated books, in Australia and the United Kingdom, respectively. (So fortuitously had the controller of BBC's children's channel CBBC, Cheryl Taylor.)

Combining entrepreneurial activity with the production of original intellectual property (IP), Egerton and Webster have always been open about the need for commercially appealing content. Just before establishing Cheeky Little Media, Egerton maintained,

The holy grail is a brand that goes for 10 or 20 years and there's lots of track records around the world-shows like Dora the Explorer and Thomas the Tank Engine-that have worked. That's the holy grail for us; to create a brand that has longevity and can spin out a whole lot of brand loyalty from kids. ${ }^{8}$

The pair considered Bottersnikes and Gumbles a valuable property on which to base a new series partly because of the books' existing familiarity among parents of young children, which effectively gave the series a built-in audience. ${ }^{9}$ Contemporary children's screen production appears to encourage a culture of reboots, including Teletubbies (2015-), Clangers (2015), Dangermouse (2015), and Thunderbirds Are Go (2016-). Industry lore suggests existing brand awareness and nostalgia among parents reduce some of the risks associated with investing in new children's productions, particularly for SVODs operating in very crowded markets. While anecdotal evidence from producers indicates merchandising opportunities rather than program sales are the most lucrative element of these rebooted children's properties, SVODs with 
big content budgets can also offer producers welcome additional licensing fee opportunities. Amazon Prime, for example, licensed the rebooted Thunderbirds Are Go in $2016 .{ }^{10}$

When Cheeky Little Media attempted to obtain the rights to Wakefield's books, they found that they had already been sold to an Australian animation company, Mighty Nice, owned by their former colleague Darren Price. Price, whose company specializes in producing animations for advertisers, agreed to collaborate with Cheeky Little Media on the production of the CGI animation. Price's involvement provided immediate access to his production studio and staff of animators, allowing the prompt production of a test sample of animation which could be used for pitching the series. ${ }^{11}$ The book rights were secured in 2012; Cheeky Little Media showed the Bottersnikes and Gumbles sample at the Asian Animation Summit in 2013. The Summit is an important annual industry event at which animators pitch samples of their shows and attempt to persuade television services to invest in their content.

The pitch attracted initial support for the series from Australian free-to-air commercial broadcaster Seven Network, for which Webster and Egerton had previously produced children's content through Ambience Entertainment. With Seven Network's attachment to the project secured, UK-based distributor Cake also came on board to support further development of the series; the distributor was able to secure deals with Netflix and the BBC, for its children's channel CBBC. Netflix at the time had largely acquired its children's animation from Dreamworks and had not previously commissioned content from any small independent production companies. However, the SVOD was attracted by the quality of the series: "They saw the test and went "wow, that could be very unique' and they jumped on."12 After a year of script development funded by the BBC, production began in 2014, quite a short production schedule for an animated series.

\section{National Policy Regimes, Children's Content, and Global Production}

Screen production companies are operating at a time when longstanding policy and funding arrangements for domestically produced content are being undermined. This is thanks in part to the "distribution revolution," ${ }^{33}$ created by the arrival of internet-distributed television services like Netflix, which have no structural connections to existing media companies. ${ }^{14}$ Much of the disruption for the children's sector has been caused by the apparent abundance of children's content from all over the world now available online from a range of providers, including YouTube, most of which are US-based commercial services. Nonetheless, many countries including Australia and the United Kingdom continue to support domestically produced children's television, a "genre" always at risk of market failure, most commonly through the vehicle of public service broadcasting. Screen content that situates children in their own cultural context and contributes to a sense of identity and citizenship is still perceived to have value. ${ }^{15}$

To support the production of domestic children's television, Australia-with a small population of twenty-two million-has had supports for locally produced children's television since 
the late 1970s. These supports include tax breaks, direct subsidies, and content quotas. ${ }^{16}$ Since 1979, aging regulatory instrument the CTS has contained content quotas for locally produced children's television, including children's or C drama, on Australia's three free-to-air commercial networks Seven, Nine, and Ten. Both live action drama and animation can be used to acquit these $\mathrm{C}$ drama quota obligations. Thus, the initial support for Bottersnikes and Gumbles came from Australia's Seven Network because it needed to invest in some local content for its C drama quotas, which are currently thirty-two hours of new content each year. ${ }^{17}$

With an Australian free-to-air broadcaster on board, Bottersnikes and Gumbles then became eligible for other national funding schemes intended to support domestically produced content, including the 20 percent television production tax rebate, the Producer Offset. ${ }^{18}$ Leading screen body Screen Australia also offers producers direct funding of up to AU\$2 million for children's content, but only if an Australian broadcaster has already committed to paying a minimum of AU\$115,000 per half hour for that content. The ABC had agreed to pay the minimum license fees required to trigger Screen Australia funding on The Adventures of Figaro Pho, but as Egerton explains,

Our challenge and the challenges for all kids' producers is the $\$ 115,000$ half hour level to trigger Screen Australia funding. Broadcasters can be unwilling to commit license fees at that level, especially on animated content ${ }^{19}$

Despite the acknowledged importance of the local, children's television in Australiaparticularly high cost, scripted, drama series-has always relied on international sales for the majority of its production budgets. ${ }^{20}$ Since the mid-2000s, animation has increasingly displaced live action as mandated hours of local content; both are permitted to be used to fill $\mathrm{C}$ drama quotas under the terms of the legislation, but animation is generally the lower cost option. ${ }^{21}$ Animation is generally cheaper to produce than live action drama, has a longer shelf life, and can be revoiced for global markets, all of which give it a significant competitive advantage. $^{22}$ Much of the animation produced to satisfy local content quotas in Australia is made with international partners, is rarely based on Australian stories, and tends to eschew Australian accents and locations, because these might hinder its international distribution. ${ }^{23}$ Thus, Bottersnikes and Gumbles was unusual because of its Australian literary pedigree and cultural specificity in terms of landscape, flora and fauna, and accents. Ironically, the achievement of this policy outcome (a rare occurrence in contemporary Australian children's television) was only possible because US-based SVOD Netflix, an increasingly effective instrument of media globalization, was persuaded to invest in the series by its UK distributor.

For SVODs like Netflix and Amazon Prime that focus on selling content to audiences, children's programs are valuable because they attract families with children to their subscription services. Certain types of content (including children's) are particularly well suited to SVODs' on-demand distribution model. ${ }^{24}$ Children's content is also valuable because it helps Netflix build brand loyalty at every stage of its audience's life cycle. In 2016, Netflix was available in 190 countries and had more than seventy-five million subscribers around the world, with only China, North Korea, Syria, and Crimea beyond its reach. In the same year, Netflix's chief content officer Ted Sarandos singled out children's content as an area 
of special importance, saying that he's "focussed on building a slate that today's kids will grow up loving." 25

Sarandos's strategy of investing heavily in original content clearly has the potential to be of significant benefit to children's screen production companies. According to UK children's television advocate Greg Childs,

The SVOD market is much hungrier than the broadcast market for new content, which is putting the value back in IP and newly generated ideas and freshness. SVOD users churn very quickly and easily but kids prevent churn, because once the child clicks on Peppa Pig on Netflix, as far as the child's concerned, Netflix is a channel. Children are used to prevent churn, so SVODs are desperately in need of constantly refreshed content. ${ }^{26}$

Nonetheless, Netflix, like all SVODs operating in Australia, is under no regulatory obligation to invest in local content and very rarely does so, despite its market penetration. In 2017, 32 percent of Australian homes had an SVOD subscription, with an estimated seven million Australians living in homes with access to Netflix and two million subscribing to the service compared with eight hundred sixty-seven thousand subscribing to the Australian-owned SVOD Stan. Approximately 2-2.5 percent of Netflix Australia's entire catalog is estimated to be Australian, compared with 9.5 percent on local offering Stan. ${ }^{27}$ While Seven Network's mandated investment in Bottersnikes and Gumbles-courtesy of national media policies for the Australian child audience-enabled the financing and distribution arrangement with the $\mathrm{BBC}$ and Netflix to occur, these coproduction arrangements were established completely outside the Australian policy context. The intersection between national policies intended to support Australian cultural representation, and the programming needs of global service Netflix facilitated the funding, production, and rapid international distribution of Bottersnikes and Gumbles. Nonetheless, in commissioning the series, Netflix was simply seeking to source branded Originals for its children's offerings; its strategies of audience capture happened to intersect with Australian media policy objectives. Netflix's actions do not reflect any willingness to deliberately invest in domestically produced content in one of its newer markets. Indeed, the company has lobbied against local content requirements in Australia, arguing that content quotas lead to low-quality programming. ${ }^{28}$

Clearly, as Australian independent producers, Webster and Egerton have benefited from Australian policy instruments such as the CTS, direct funding subsidies from Screen Australia, and local tax schemes like the Producer Offset intended to support content that situates Australian children in their own cultural context. These supports for domestically produced content allowed them to harness the BBC's editorial expertise and a US-based SVOD's financial largesse and streaming capacity to scale up the production and, crucially, the distribution of Bottersnikes and Gumbles. While their previous shows sold in international markets, the sheer scale and simplicity of internet-distributed television services like Netflix, which release content in forty countries on the same day, is new for Egerton and Webster.

And in aligning the content needs of national and global television providers, they have created a children's brand which has well and truly jumped the fence from its domestic beginnings on Australian linear television. 


\section{The Creative Circumstances of Bottersnikes and Gumbles}

As Netflix increased its investment in original content including children's (its content budget was AU\$6 billion in 2017), the SVOD has developed coproduction arrangements with cashstrapped public service broadcasters, including Australia's ABC and the United Kingdom's $\mathrm{BBC}$. Some of the UK/BBC commissions have been live action dramas, including a rebooted adaptation of Jill Murphy's children's books The Worst Witch (2017-), a coproduction with the BBC and German PSB ZDF. Netflix has also commissioned animation, including a reboot of Watership Down, again based on the book and again a coproduction with the BBC. The SVOD's recent live action drama reboot The Legend of Monkey (2018-), which was filmed in New Zealand, is a coproduction with Australia's public service children's channel ABCME.

For Netflix, coproducing content with the BBC has two advantages. First, it establishes a connection with the BBC brand, for quality and excellence in programming, which is trusted by parents all over the world. Second, it allowed the relatively inexperienced SVOD access to BBC production expertise, decades of experience in high-quality screen production, and its staff's creative insights and knowledge of the sector. But as Michael Carrington, head of children's at Australian PSB the ABC, explains, Netflix has moved quickly in the two years since Bottersnikes and Gumbles was commissioned to shore up its creative expertise. In September 2017, for example, the SVOD recruited Melissa Cobb, previously chief creative officer and head of studio for Oriental DreamWorks, as its vice president of kids and family:

Netflix didn't necessarily have creative editorial roles. They're a technology company. However, recently they employed a vice president of kids and family to oversee the creation and acquisition of content. Collaborations with Netflix seem to be more editorially aligned with a traditional broadcasting coproduction model, with creative executives on both sides overseeing creative direction. ${ }^{29}$

Netflix's practice, of conceding creative control to the $\mathrm{BBC}$ in the absence of its own creative practitioners, was evident with Bottersnikes and Gumbles. Although Netflix was the largest cash investor in the series, the $\mathrm{BBC}$ took the creative lead. Webster suggests that "the $\mathrm{BBC}$ have such renown around the world that when the $\mathrm{BBC}$ is involved no other broadcaster feels the need to contribute." ${ }^{30}$ Cheeky Little Media was fortunate that Netflix's hands-off approach meant the producers were able to avoid having to accommodate the conflicting requirements of multiple channels and investors, which can become extremely difficult for children's producers operating in global markets. ${ }^{31}$

With the acquisition of the book rights and the economics of production budgets completed, Webster and Egerton were able to concentrate on the creative process of production. Having grown up with the books themselves, they drew on their memories of the print version of the story. These included specifically Australian details, such as the bush, and native animals including koalas. As Webster explains,

We were trying to remember all the things that really sparked our imagination as kids. One of them was the feeling of the Australian bush, and the incredible creatures which, although fictitious, had 
reptilian elements. It was almost like the Bottersnikes were a cross between a crocodile and a bunyip and the Gumbles were sort of koala-ish. But the fantasy element was a huge drawcard and I distinctly remember the Bottersnikes as being hugely imaginative creatures. So it was fantastic to work on that and bring it to life. ${ }^{32}$

Nonetheless, the book's illustrations, which were produced in the 1960s and 1970s, required updating for a contemporary audience. So too did the characters, so that the series' writers could develop sufficient story lines to fill for fifty-two episodes. According to Webster,

If you pick up the book it feels quite old-fashioned, definitely something from the 1970s. So we struggled with that a little bit. We didn't have to change the Bottersnikes at all, they're the same as the book. The Gumbles though were an amorphous group, like the Smurfs. You couldn't distinguish one from the other. There were no real lead characters. But we had to take the Gumbles and turn them into lead characters, into the heroes with strong personalities to challenge the Bottersnikes, which was a break from the book. ${ }^{33}$

The series head writer who was based in the United Kingdom worked with a team of approximately eight writers split between the United Kingdom and Australia. Netflix did not provide notes on rough cuts or scripts, but "just left us to get on with it." very closely involved creatively, including seeing every single version of the scripts. Webster concedes it was a difficult show to write because of the distinctive tone of the books. But as the key creatives, Webster, Egerton, and Price were very familiar with the books and felt confident rejecting an episode pitch if they felt it was wrong: "We were acting as guardians of the original book. We knew the world and what would work and what wouldn't." ${ }^{35}$

Producing Bottersnikes and Gumbles involved thirty artists and model makers, with the production process beginning with the storyboard artists, who create the first visual format of the show, based on the scripts they are given. As creative director, Webster played a key role in the organization of the creative process. He believes that storyboarding underpins the series' narrative and wanted to retain control of the process:

I personally feel that the storytelling really happens in the storyboarding. So we insisted on controlling that, and that was done in-house at Cheeky Little. So directing, storyboarding, animatic were all controlled in house. ${ }^{36}$

The BBC was also closely involved in the casting process, with voice recording for the series entirely completed in the United Kingdom. Seven UK-based actors, three of whom were Australian, completed all the voices, with individual actors voicing as many as three characters. The use of Australian creative labor ensured the production complied with the local content regulations mandated by Australian media regulator the Australian Communication and Media Authority (ACMA), without which it would not qualify for the C drama classification. Without this classification, the series could not be used by Seven Network to fill its quotas and would therefore have no value to the broadcaster.

Bottersnikes and Gumbles is unusual in the current children's television production ecology, given its inclusion of Australian flora and fauna and the fact that the characters have a combination of British and Australian accents. According to Webster, having the series look and sound Australian was appealing to the BBC, and initially to Netflix: 
The setting, to us is clearly Australian and they were very happy with that. The fact that the books were Australian and in our pitch the first piece of test animation we did was Australian bush-they absolutely loved that. So there wasn't any pushback about the Australian setting or any of that. ${ }^{37}$

After the series was dubbed with the combination of UK and Australian accents, Netflix decided, however, that Bottersnikes and Gumbles should be dubbed with American accents for the US Netflix market. Traditionally, American audience have little tolerance of non-US accents, which gives such programs a cultural discount in the United States. ${ }^{38}$ Webster explains,

So once Netflix heard the voices they thought it could be problematic, not extreme accents for our ear but to the American ear perhaps. So they did a casting and we got to hear all of the American voices. I don't think you'd ever match the quality of the cast that we put together-we had Miriam Margoyles for example-but it's pretty good. ${ }^{39}$

Children's television services financed by US-based private companies are normally localized for consumption outside the United States, not in the United States. For example, the Disney channel will have a patina of localization in non-US territories, by including homegrown presenters, national competitions, and small amounts of locally produced content. Individual programs will be dubbed for distribution in non-English-speaking territories. ${ }^{40}$ In the case of Bottersnikes and Gumbles, however, the globally distributed series was localized for twenty non-English-speaking territories and the United States. With the exception of the use of US voices, Netflix remained largely hands-off during the production process. They did, however, support Webster's creative decision making when certain ideas were initially rejected by the $\mathrm{BBC}$. As he recounts,

We were surprised-we expected more input from Netflix. We sent them every script, they didn't comment. The only time we had to invoke their opinion was on the opening titles, which were 2D. It's a bit of trend, to do beautiful 2D titles in CGI film. The BBC were reluctant at first, but ultimately Netflix supported it. ${ }^{41}$

As is common in contemporary screen production, the actual animation process for Bottersnikes and Gumbles was outsourced through several territories including China and India. Globally dispersed production systems have increasingly come to characterize all kinds of film and television production. ${ }^{42}$ Various aspects of production can be undertaken by different providers in different regions, depending on the availability of creative labor, state subsidies, and location inducements. ${ }^{43}$ One of the advantages of the globally dispersed production system that characterizes much contemporary animation production is in the access to the best creative workers, regardless of their location. Production can also constantly occur, in different time zones, which can increase creativity and reduce costs. ${ }^{44}$

Attempts to minimize production costs are integral to all screen productions. They include the use of location inducements, the accessing of local screen subsidies and tax incentives, and the outsourcing of labor-intensive production processes. ${ }^{45}$ But producing content for Netflix brings an extra set of financial pressures as the SVOD does not pay its content providers until the finished series is delivered. As a result, the production company has to cash flow their entire license fee. The SVOD also requires the production company to dub their 
children's content into eighteen languages, at their cost, but using Netflix's preferred providers. The dubbing process alone can add six months and millions of dollars onto production schedules and budgets.

Netflix's willingness to pay the vast majority of Bottersnikes and Gumbles's production costs, yet concede creative control to a public service broadcaster (but be prepared to intervene to back a producer's creative instincts where necessary) is unusual in comparison with most other children's screen production cultures. The need to accommodate the creative visions and programming needs of multiple television services with wildly different expectations of the content in which they have invested has had negative consequences for Australian producers in the past. The animated series Animalia, based on the Australian book of the same and a coproduction between Australia's Ten Network, the BBC, pay-TV channel Nickelodeon, and Canada's CBC nearly bankrupted its production company and left producer Ewan Burnett vowing never again to attempt a similar project. ${ }^{46}$ So in the case of Bottersnikes and Gumbles, the production processes were less difficult because of the BBC's editorial control. Nonetheless, the need to cash flow production, including the compulsory high-cost, largescale dubbing processes, puts a strain on producers' financial resources. Furthermore, Netflix's refusal to release ratings data publicly, or even to producers, presents a further set of difficulties. This is because for children's television producers, the creation of licensed products frequently underpins the cost of the content they produce, particularly animation. ${ }^{47}$ Webster and Egerton were keen to monetize the brand they had created, beyond its license fees, but Netflix's refusal to share its viewing data or support the development of the brand made the creation of licensed products more difficult. Webster explains,

There's not really the support for the brand that we were expecting. They don't share information. The only way we can find out is through social media. It's very hard, we need a lot more feedback. ${ }^{48}$

Although the SVOD may not have directly supported the Bottersnikes and Gumbles brand in the way that its creators would have liked, internet-distributed television delivered by highly competitive providers like Netflix brings significant benefits in terms of rapid, virtually simultaneous global distribution. In the case of this unofficial coproduction between Netflix and the $\mathrm{BBC}$, the latter initially had exclusive rights to Bottersnikes and Gumbles. As CBBC is the premium children's platform in the United Kingdom, this exclusive window provided significant benefits in terms of its visibility with UK audiences and the concomitant generation of brand awareness, both of which are important for the creation of licensed products associated with the series. Netflix's global distribution extended that brand recognition rapidly, in multiple territories at once. In contrast to the SVOD and BBC's treatment of Bottersnikes and Gumbles as a valuable property, Seven Network, in what is a standard practice for Australia's commercial networks, scheduled Bottersnikes and Gumbles irregularly; according to Webster, "it was all over the place on Network Seven, four eps here, four eps there, not many people

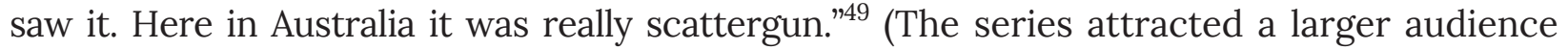
when it was shown on PSB channel ABCME in Australia). In terms of licensed products, new books based on the new series are being published, and a platform-specific game which was originally commissioned by the $\mathrm{BBC}$ has been created. Cheeky Little Media has retained the series' IP and the rights to distribute the game worldwide. ${ }^{50}$ For children's content producers negotiating new screen production ecologies and adapting to the programming needs of 
internet-distributed streaming services, Netflix's substantial content budgets and global reach are extremely attractive. Nonetheless, the SVOD's refusal to release its viewing data, pay up front for its commissions, or cover the dubbing costs itself is onerous. Given the oversupply of content producers in the children's production ecology, however, producers who have had negative experiences making Netflix commissions appear unlikely to voice their misgivings too loudly.

\section{Discussion}

Longstanding policy settings and funding mechanisms intended to support domestically produced children's content in Australia and the United Kingdom are challenged by the increasing popularity of internet-distributed television services with young audiences. At the time of writing, the Australian government is conducting three reviews that address the future of local content regulations, the sustainability of Australia's screen production industries, and the cultural and economic value of local children's television. While the sole report released to date has recommended the introduction of a levy for local children's content for SVODs ${ }^{51}$ Netflix has already made clear its objections to any local content obligations. ${ }^{52}$ In the United Kingdom, children's content quotas were removed from commercial free-to-air broadcasters ITV, Channel 4, and Channel 5 in 2003, leading to the decimation of the UK children's screen production industry. In 2017, in recognition of the catastrophic effects of their absence on domestic screen production, Ofcom's powers to implement children's content quotas were restored; the UK regulator is currently conducting a review of the provision of children's content by UK PSBs. In 2017, the BBC also announced an extra $£ 34$ million for school age and preschool children's content, most of which will be spent on online offerings, partly to combat the influence of Netflix on UK children. ${ }^{53}$ The United Kingdom also recently introduced a contestable funding scheme, with up to $£ 60$ million to be made available for children's content creators over three years from 2019. ${ }^{54}$

Despite the BBC's best efforts to compete with Netflix in what the PSB is framing as something of a David and Goliath battle, the PSB, like its Australian counterpart, continues to collaborate on the production of children's screen content with its rival. Under these arrangements, the SVOD benefits from decades of PSB production and editorial expertise, and reputational value, to develop content which is swiftly branded as a Netflix Original. That content is then distributed on a service, every aspect of which is at odds with the principles of public service broadcasting. As an algorithm-driven, subscription service dependent on high-speed internet access, Netflix is designed to offer children (in sufficiently affluent homes) a selection of content funneled down from what they already know and like. It thus narrows rather than broadens the viewing choices of the minority to whom it is available at a direct consumer cost, the antithesis of PSB principles.

The BBC's collaboration with Netflix is not the first time the PSB has produced content with a new market entrant whose programming budgets are greater than its production expertise and reputational value. The BBC's influential partnership with Discovery Network, engendered by the 1994 establishment of commercial arm BBC Worldwide, was intended to develop BBC factual programming into a global brand through coproductions, joint venture channels and 
the US distribution of the channel BBC America. ${ }^{55}$ The substantial influx of funding from Discovery-as much as US\$226 million between 1998 and 2004-led to the development of spectacular and lucrative BBC factual programs, including the Walking With ... brand, and joint venture network Animal Planet. ${ }^{56}$ The combination of PSB creative talent, and Discovery cash and expertise in channel development benefited both partners from 1998 to 2014, establishing the BBC as global supplier of blockbuster factual programming while ensuring Discovery had access to unique, high-quality content that distinguished it from its competitors. ${ }^{57}$

The current arrangements between PSBs like the BBC and Australia's ABC, and Netflix, appear very different. While the SVOD is contributing the majority of production costs as Discovery did, the resulting (unofficial) coproductions are generally branded as Netflix Originals, with Netflix holding the rights to these children's series in all territories. In contrast, much of the $\mathrm{BBC} /$ Discovery content was only available to Discovery in the United States, whereas the $\mathrm{BBC} /$ Discovery joint venture channels allowed global promotion of the BBC brand and programs. ${ }^{58}$ Furthermore, Netflix's role as both a producer and a distributor of content, particularly high-quality drama, for audiences of all ages suggests the SVOD poses a much greater threat to PSB audiences than pay-TV services like the United Kingdom's BSkyB and Australia's Foxtel ever did. These satellite services traditionally relied on investment in sport, movies, and niche thematic content, including news to drive subscriptions, rather than in quality drama. Much of their output has a shorter shelf life than the drama in which Netflix is investing, including its children's offerings. As a streaming service which both produces and distributes original content, Netflix is making an enormous investment in attracting and retaining subscribers. It is also building a substantial and enduring program catalog, which is being shaped in part by PSB expertise, including in its children's offerings.

The production of Netflix's first children's Original Bottersnikes and Gumbles is characterized then by a series of apparent paradoxes. First, the $52 \times 11$-minute series was largely financed by a global SVOD that releases its shows in forty countries and eighteen languages simultaneously and represents a collaboration between Netflix, ostensible rival the BBC, and an Australian free-to-air commercial broadcaster. It was made by a transnational creative labor force operating in dispersed production locations across Australia, the United Kingdom, and India. Yet despite its undeniably global provenance, it constitutes a rare example of cultural specificity in children's animation being clearly Australian, based on Australian stories, with identifiably Australian visual signifiers and, in one version at least, Australian accents. The series is emblematic regardless of the globalized processes of media production and distribution that are transforming how television is made, and experienced by its audiences, particularly the child audience.

The case study presented here reveals also some of the ways producers of contemporary children's animation are adapting to the distribution revolution. It also shows how internetdistributed children's television services are interacting with longstanding policy frameworks while reshaping funding and production practices. The effects of the activities of SVODs like Netflix deserve careful analysis, because the SVOD continues to operate outside the various national regulatory mechanisms that place local content obligations on free-toair commercial television, PSBs, and pay-TV channels in Australia and the United Kingdom. They also require scrutiny because SVODs appear to benefit directly from decades of taxpayer-funded PSB knowledge, and indirectly from state supports intended to support 
locally produced content, despite a stated aversion to any kind of local content obligations upon themselves. Netflix's UK-produced live action tween horse-riding drama Free Rein (2015) had an American lead actor and was made to appeal to international audiences. Its production was nonetheless subsidized by UK tax breaks intended to support national cultural representation. Naturally, SVODs have been welcomed by producers because of their willingness to invest in new commissions and because their investment provides an additional licensing window and welcome source of extra funding. Nonetheless, Australian and UK producers at this stage remain dependent on national, linear broadcasters whose initial commissions allow them to access the national funding schemes and tax incentives that continue to subsidize the cost of domestically produced children's television.

Bottersnikes and Gumbles is emblematic then of the "messy and complicated interactions"59 occurring between self-regulating global SVODs and contemporary children's screen industries; the latter have always been characterized at the national level by high levels of regulatory intervention and state support. Its production nonetheless represents a serendipitous combining of Australian children's literature, talented and experienced animation producers and distributors, and an SVOD with generous program budgets and a willingness to take a creative backseat on this Original. This alignment of the planets in the children's production ecology has resulted in a high-quality, culturally specific children's animated series. Whether or not these circumstances can be recreated for future screen adaptations is far from clear, however. The Australian-ness of Netflix's first children's Original is most likely anomalous, a creative quirk that is testament to the artistic talents and business acumen of its producers, rather than indicative of a resurgence in culturally specific content funded by American SVODs. As the UK experience demonstrates, levels of domestically produced children's television plummet when content quotas are removed, with or without the presence of internetdistributed television services like Netflix.

${ }^{1}$ This research was supported by the Australian Research Council (ARC) grant DE160100313.

${ }^{2}$ Anna Potter is an Australian Research Council DECRA Fellow and Senior Lecturer in Screen and Media Studies at the University of the Sunshine Coast in Australia. She is the author of Creativity, Culture, and Commerce: Producing Australian Children's Television with Public Value (Intellect, 2015).

${ }^{3}$ Patricia Edgar, Bloodbath: A Memoir of Australian Children's Television (Melbourne: Melbourne University Press, 2006); Anna Potter, Creativity, Culture and Commerce: Producing Australian Children's Television with Public Value (Bristol: Intellect, 2015); Brian Simpson, Children and Television (London: Continuum, 2004).

${ }^{4}$ Gillian Doyle, "Multi-Platform Media and the Miracle of the Loaves and Fishes," Journal of Media Business Studies 12 (1, 2015): 49-65.

${ }^{5}$ Brett Mills, "After the Interview," Cinema Journal 47 (2, 2008): 148-54.

${ }^{6}$ Jeanette Steemers, Creating Preschool Television (Basingstoke: Palgrave MacMillan, 2010).

${ }^{7}$ Michael Curtin, "Thinking Globally from Media Imperialism to Media Capital," in Media Industries: History, Theory, and Method, ed. Jennifer Holt and Elisa Perren (West Sussex: Wiley Blackwell, 2009), 108-19. 
${ }^{8}$ Patrick Egerton, interview by Anna Potter, April 23, 2013, Tape recording, Sydney.

${ }^{9}$ David Webster, interview by Anna Potter, November 7, 2016, Tape recording, Brisbane.

${ }^{10}$ Anna Potter, "Funding Contemporary Children's Television:How Digital Convergence Encourages Retro Reboots," International Journal on Media Management 19 (2, 2017): $108-22$.

${ }^{11}$ David Webster, interview by Anna Potter, November 7, 2016.

12 Ibid.

${ }^{13}$ Michael Curtin, Kevin Sanson, and Jennifer Holt, "Introduction: The Making of a Revolution," in Future of Film and Television, ed. Kevin Sanson, Michael Curtain, and Jennifer Holt (Berkeley: University of California Press, 2014), 2.

${ }^{14}$ Kevin McDonald, "Digital Dreams in a Material World: The Rise of Netflix and Its Impact on Changing Distribution and Exhibition Patterns," Jump Cut 55 (2013), http://ejumpcut.org/archive/jc55.2013/McDonaldNetflix/index.html.

${ }^{15}$ Potter, Creativity, Culture and Commerce; Jeanette Steemers, "International Perspectives on the Funding of Public Service Media Content for Children," Media International Australia 163 (1, 2017): 42-55.

${ }^{16}$ Kate Aisbett, Twenty Years of C: Children's Programs and Regulation: 1979-1999 (Sydney: Australian Broadcasting Authority, 2000); Potter, Creativity, Culture and Commerce.

${ }^{17}$ Australian Communications and Media Authority, Children's Television Standards (Sydney: Australian Communications and Media Authority, 2016).

${ }^{18}$ Screen Australia, "Guidelines: What Is the Producer Offset," 2017, https://www. screenaustralia.gov.au/funding-and-support/producer-offset/guidelines / about-the-producer-offset.

${ }^{19}$ Patrick Egerton, interview by Anna Potter, April 23, 2013.

${ }^{20}$ Stuart Cunningham and Elizabeth Jacka, Australian Television and International Mediascapes (Cambridge: Cambridge University Press, 1996).

${ }^{21}$ Screen Australia, "Child's Play: Issues in Australian Children's Television 2013," 2013.

${ }^{22}$ Steemers, Creating Preschool Television.

${ }^{23}$ Potter, Creativity, Culture and Commerce.

${ }^{24}$ Amanda Lotz, Portals: A Treatise on Internet-Distributed Television (Michigan: Maize Books, 2017).

${ }^{25}$ Natalie Jarvie and Lesley Goldberg, "Ted Sarandos on Netflix Programming Budget: 'It'll Go up' from \$6 Billion," Hollywood Reporter, July 27, 2016, http://www.hol lywoodreporter.com/live-feed/ted-sarandos-netflix-programming-bud get-915020.

${ }^{26}$ Greg Childs, interview by Anna Potter, August 20, 2015, Tape recording, London.

${ }^{27}$ Ramon Lobato and Alexa Scarlata, "Australian Content in SVOD Catalogues: Availability and Discoverability," Submission to the Australian and Children's Screen Content Review, 2017.

${ }^{28}$ David Richards, "Netflix Gives Local Content Producers Two Finger Salute," Channelnews, May 7, 2018, https://www.channelnews.com.au/netflix-gives-localcontent-producers-two-finger-salute/.

${ }^{29}$ Michael Carrington, interview by Anna Potter, November 25, 2017, Tape recording, Sunshine Coast. 
${ }^{30}$ Webster, interview by Anna Potter, November 7, 2016.

${ }^{31}$ Potter, Creativity, Culture and Commerce.

${ }^{32}$ Webster, interview by Anna Potter, November 7, 2016.

33 Ibid.

${ }^{34}$ Ibid.

${ }^{35}$ Ibid.

${ }^{36}$ Ibid.

${ }^{37}$ Ibid.

${ }^{38}$ Hoskins, Colin and Stuart McFadyen, "The U.S. Competitive Advantage in the Global Television Market," Canadian Journal of Communication 16 (2, 1991): 1-12.

${ }^{39}$ Webster, interview by Anna Potter, November 7, 2016.

${ }^{40}$ Potter, Creativity, Culture and Commerce.

${ }^{41}$ David Webster, interview by Anna Potter, November 26, 2017, Tape recording, Sunshine Coast.

${ }^{42}$ Jean Chalaby, "Producing TV Content in a Globalized Intellectual Property Market: The Emergence of the International Production Model," Journal of Media Business Studies 9 (3, 2012): 19-39.

${ }^{43}$ Michael Curtin and Kevin Sanson. "Precarious Creativity: Global Media, Local Labor." in Precarious Creativity: Global Media, Local Labor, ed. Kevin Sanson and Michael Curtain (Oakland: University of California Press, 2016), 1-19.

${ }^{44}$ Potter, "Funding Contemporary Children's Television."

${ }^{45}$ Ben Goldsmith and Tom O'Regan, The Film Studio: Film Production in the Global Economy (Lanham: Rowman \& Littlefield, 2006).

${ }^{46}$ Potter, "Funding Contemporary Children's Television."

${ }^{47}$ Steemers, Creating Preschool Television.

${ }^{48}$ David Webster, interview by Anna Potter, November 26, 2017.

${ }^{49}$ Ibid.

${ }^{50}$ Webster, interview by Anna Potter, November 7, 2016.

${ }^{51}$ Standing Committee on Communications and the Arts, "Report on the Inquiry into the Australian Film and Television Industry," House of Representatives, 2017.

${ }^{52}$ Don Grove, "Netflix Argues against Local Content Quota in Oz," 2017, https://www. if.com.au/netflix-argues-local-content-quota-oz/.

${ }^{53}$ BBC, "BbC Making 34m Investment in Children's Content," July 4, 2017, http:// www.bbc.co.uk/news/uk-40489812.

${ }^{54}$ Gov UK, “£60 Million Boost to UK Children’s Television," 2017, https://www.gov. uk/government/news/60-million-boost-to-uk-childrens-television

${ }^{55}$ Jeanette Steemers, "Broadcasting for the Digital Age between Culture and Commerce: The Problem of Redefining Public Service," Convergence 5 (3, 1999): 44-67; Mjøs J. Ole, "Marriage of Convenience? Public Service Broadcasters' CrossNational Partnerships in Factual Television," The International Communication Gazette 73 (3, 2011): 181-97.

${ }^{56}$ Mjøs, "Marriage of Convenience?"

${ }^{57}$ Ibid.

${ }^{58}$ Ibid.

${ }^{59}$ Curtin, "Thinking Globally from Media Imperialism to Media Capital," 111. 


\section{Bibliography}

Aisbett, Kate. Twenty Years of C: Children's Programs and Regulation: 1979-1999. Sydney: ABA, 2000.

Australian Communications and Media Authority. Children's Television Standards. Sydney: Australian Communications and Media Authority, 2016.

BBC. "Bbc Making 34m Investment in Children's Content." July 4, 2017. http://www.bbc. co.uk/news/uk-40489812.

Carrington, Michael. Interview by Anna Potter. November 25, 2017.

Chalaby, Jean. "Producing TV Content in a Globalized Intellectual Property Market: The Emergence of the International Production Model." Journal of Media Business Studies 9, no. 3 (2012): 19-39.

Childs, Greg. Interview by Anna Potter. August 20, 2015.

Cunningham, Stuart, and Elizabeth Jacka. Australian Television and International Mediascapes. Cambridge: Cambridge University Press, 1996.

Curtin, Michael. "Thinking Globally from Media Imperialism to Media Capital." In Media Industries: History, Theory, and Method, edited by Jennifer Holt and Elisa Perren, 108-19. West Sussex: Wiley Blackwell, 2009.

Curtin, Michael and Kevin Sanson. "Precarious Creativity: Global Media, Local Labor." In Precarious Creativity: Global Media, Local Labor, edited by Kevin Sanson and Michael Curtain, 1-19, 2016.

Curtin, Michael, Kevin Sanson, and Jennifer Holt. "Introduction: The Making of a Revolution." In Future of Film and Television, edited by Kevin Sanson, Michael Curtain, and Jennifer Holt, 1-17. Berkeley: University of California Press, 2014.

Doyle, Gillian. "Multi-Platform Media and the Miracle of the Loaves and Fishes." Journal of Media Business Studies 12, no. 1 (2015): 49-65.

Edgar, Patricia. Bloodbath: A Memoir of Australian Children's Television. Melbourne: Melbourne University Press, 2006.

Egerton, Patrick. Interview by Anna Potter. April 23, 2013.

Goldsmith, Ben, and Tom O'Regan. The Film Studio: Film Production in the Global Economy. Lanham: Rowman \& Littlefield, 2006.

Gov UK. “£60 Million Boost to Uk Children’s Television.” 2017. https://www.gov.uk/govern ment/news /60-million-boost-to-uk-childrens-televisionGrove.

Grove, Don. "Netflix Argues against Local Content Quota in Oz." September 27, 2017. https:// www.if.com.au/netflix-argues-local-content-quota-oz/.

Hoskins, Colin, and Stuart McFadyen. "The Us Competitive Advantage in the Global Television Market." Canadian Journal of Communication 16, no. 2 (1991): 1-12. 
Jarvie, Natalie, and Lesley Goldberg. “Ted Sarandos on Netflix Programming Budget: 'It'll Go up' from \$6 Billion." Hollywood Reporter, July 27, 2016.

Lobato, Roman, and Scarlata Alexa. "Australian Content in Svod Catalogues: Availability and Discoverability." Submission to the Australian and Children's Screen content review, 2017.

Lotz, Amanda. Portals: A Treatise on Internet-Distributed Television. Michigan: Maize Books, 2017.

McDonald, Kevin. "Digital Dreams in a Material World: The Rise of Netflix and Its Impact on Changing Distribution and Exhibition Patterns." Jump Cut 55 (2013).

Mills, Brett. "After the Interview." Cinema Journal 47, no. 2 (2008): 148-54.

Mjøs, J. Ole. "Marriage of Convenience? Public Service Broadcasters' Cross-National Partnerships in Factual Television." The International Communication Gazette 73, no. 3 (2011): 181-97.

Potter, Anna. Creativity, Culture and Commerce: Producing Australian Children's Television with Public Value. Bristol: Intellect, 2015.

Potter, Anna. "Funding Contemporary Children's Television: How Digital Convergence Encourages Retro Reboots." International Journal on Media Management 19, no. 2 (2017): 108-22.

Richards, David. "Netflix Gives Local Content Producers Two Finger Salute." Channelnews, May 7, 2018. https://www.channelnews.com.au/netflix-gives-local-contentproducers-two-finger-salute/.

Screen Australia. "Child's Play: Issues in Australian Children's Television 2013." 2013.

Screen Australia. "Guidelines: What Is the Producer Offset." 2017. https://www.screenaustralia .gov.au/funding-and-support/producer-offset/guidelines/about-the-produceroffset.

Simpson, Brian. Children and Television. London: Continum, 2004.

Standing Committee on Communications and the Arts. "Report on the Inquiry into the Australian Film and Television Industry." House of Representatives, 2017.

Steemers, Jeanette. "Broadcasting for the Digital Age between Culture and Commerce: The Problem of Redefining Public Service." Convergence 5, no. 3 (1999): 44-67.

Steemers, Jeanette. Creating Preschool Television. Bassingstoke: Palgrave MacMillan, 2010.

Steemers, Jeanette. "International Perspectives on the Funding of Public Service Media Content for Children." Media International Australia 163, no. 1 (2017): 42-55.

Webster, David. Interview by Anna Potter. November 7, 2016.

Webster, David. Interview by Anna Potter. November 26, 2017. 